\title{
IMPLEMENTASI METODE NAÏVE BAYES CLASSIFIER UNTUK SELEKSI ASISTEN PRAKTIKUM PADA SIMULASI HADOOP MULTINODE CLUSTER
}

\author{
Maryamah $^{1}$, Moh. Fadel Asikin ${ }^{2}$, Daisy Kurniawaty ${ }^{3}$, Selly Kurnia Sari ${ }^{4}$, Imam Cholissodin ${ }^{5}$ \\ 1,2,3,4,5Fakultas Ilmu Komputer Universitas Brawijaya \\ Email: ${ }^{1}$ maryamahfaiso102@gmail.com, ${ }^{2}$ fadelasikin@gmail.com, ${ }^{3}$ daisyniaa@gmail.com,

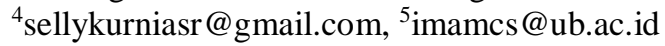

(Naskah masuk: 1 Oktober 2016, diterima untuk diterbitkan: 26 Desember 2016)

\begin{abstract}
Abstrak
Pemilihan asisten pada praktikum dialami oleh berbagai universitas di Indonesia salah satunya di Fakultas Ilmu Komputer (FILKOM) Universitas Brawijaya (UB). Dalam pemilihan asisten praktikum ada beberapa proses yang harus dilalui. Proses pemilihan yang ada di FILKOM masih dalam bentuk manual. Adapun proses yang dijalani dalam pemilihan asisten praktikum diantaranya adalah tes administrasi, tes live coding, dan tes mengajar. Dalam penentuan penerimaan asisten praktikum tersebut berdasarkan hasil tes yang telah dilakukan. Kendala yang dihadapi adalah kemiripan hasil tes pada ketentuan tertentu yang menyebabkan kerancuan proses pemilihan asisten praktikum. Dari permasalahan tersebut penulis melihat suatu peluang untuk membuat sistem yang mampu menyeleksi dengan cara melakukan hasil klasifikasi tertinggi terhadap hasil tes yang dilakukan oleh calon asisten praktikum. Penelitian ini menggunakan Hadoop dengan menerapkan metode Nä̈ve Bayes yang diangap mampu menghasilkan klasifikasi yang akurat, sehingga dapat mempermudah seorang dosen dalam memilih asisten praktikum dengan kualitas yang baik.
\end{abstract}

Kata kunci: big data, klasifikasi, nä̈ve bayes, hadoop

\begin{abstract}
Selection of the lab assistants experienced by various universities in Indonesia one of them in the Faculty of Computer Science (FILKOM) University of Brawijaya (UB). In the selection of lab assistant, there is some process to be followed. The election process is in FILKOM still in manual form. The process according to which the election is a test lab assistant include administration, test live coding, and test of teaching. In determining the lab assistant acceptance is based on the tests that have been carried out. Obstacles encountered is the similarity test results on the specific provisions that caused confusion electoral process lab assistant. Of these issues, the authors saw an opportunity to create a system that is able to select a way to the highest classification results against the results of tests conducted by the lab assistant candidates. This study uses Hadoop with Nä̈ve Bayes applying methods as may be capable of producing an accurate classification, so as to facilitate a lecturer in choosing a lab assistant with good quality.
\end{abstract}

Keywords: big data, classification, naïve bayes, hadoop

\section{PENDAHULUAN}

Perkembangan teknologi saat ini membawa kita pada perubahan hampir dari semua aspek di kehidupan. Dalam menentukan sesuatu, manusia pasti dihadapkan banyak pilihan. Dengan adanya pilihan yang benar, akan sangat mempengaruhi kehidupan manusia itu sendiri. Seiring berkembangnya teknologi, perlu dikembangkan dan juga ditingkatkan suatu sumber daya manusia agar semakin berkualitas. Permasalahan seleksi menentukan asisten praktikum banyak dialami di berbagai universitas di Indonesia, khususnya di Fakultas Ilmu Komputer (Filkom) Universitas Brawijaya.

Proses seleksi pada asisten praktikum, di Filkom masih menggunakan cara yang manual. Proses pemilihan asisten praktikum dilakukan dengan menjalani beberapa tes yang sudah ditentukan, yaitu melalui tiga tahap tes diantaranya tes administrasi, tes live coding, dan tes mengajar. Untuk penentuannya dilihat dari hasil tes yang sudah dilakukan sebelumnya. Kemiripan hasil nilai tes pada ketentuan tertentu dapat mengakibatkan kerancuan pada proses pemilihan asisten praktikum, serta dapat berpengaruh pada kualitasnya. Dan sangat diharapkan agar pemilihan asisten praktikum terpilih secara tepat. Untuk menghindari kerancuan hasil, sangat dibutuhkannya suatu sistem yang mampu membantu dalam seleksi pemilihan asisten praktikum baru dengan hasil seleksi yang tepat.

Pada penelitian oleh (Kalamsyah, 2014) yaitu tentang aplikasi untuk pemilihan asisten praktikum dan juga lab yang berbasis web menggunakan metode pengerjaan SDLC waterfall pada tahap implementasi. Orang yang terlibat dalam aplikasi tersebut adalah seorang laboran sebagai admin yang 
mempunyai akses penuh dalam mengelola infomasi seleksi, melakukan input nilai, dan melihat hasil perangkingan. Untuk perhitungan seleksi menggunakan metode Analytic Hierarchi Process. Hasil dari penelitian tersebut, laboran dapat mengetahui nilai paling tinggi sampai nilai paling rendah dari semua hasil seleksi. Hasil seleksi di pilih dengan nilai tes asisten baru dengan nilai tertinggi.

Selanjutnya penelitian yang dilakukan oleh (Sholihah, 2013), membahas mengenai penentuan jumlah UKT di Universitas Trunojoyo Madura. Penentuan UKT tersebut berdasarkan kriteria yang sesuai. Dalam pembuatan sistem, peneliti menggunakan metode Naïve Bayes Classifier (NBC). Hasil yang didapatkan pada skenario satu yaitu $90 \%$, dan skenario hasil dua data kategori $78 \%$.

Kemudian penelitian Naive Bayes Classifier oleh (Kusumadewi, 2009) adalah penggunaan alat ukur antropometri sebagai variabel masukan dalam pengklasifikasian status gizi manusia. Untuk mendapatkan hasil yang optimal terdapat beberapa pedoman antropometri yaitu usia dan berat badan, tinggi dan panjang badan, serta lingkar lengan atas. Dalam penelitian ini didapatkan 5 golongan untuk status gizi, diantaranya berat kurang, berat normal, obesitas kurang, obesitas sedang, dan obesitas berat. Untuk klasifikasi status gizi metode yang digunakan adalah metode Naive Bayes Classiffier dengan hasil akurasi cukup tinggi yaitu 93,2\% .

Berdasarkan permasalahan di atas, maka dibuat suatu sistem yang mampu menyeleksi dengan cara melihat hasil klasifikasi tertinggi terhadap hasil tes yang dilakukan oleh calon asisten praktikum. Penelitian ini menggunakan konsep Big Data yang seiring berjalannya waktu data yang digunakan akan semakin besar sebagai data histori yang dikumpulkan. Pada konsep tersebut menggunakan Hadoop yang dapat memproses data dalam ukuran besar. Metode yang digunakan adalah Nä̈ve Bayes karena dianggap mampu menghasilkan klasifikasi yang akurat, sehingga dapat mempermudah seorang dosen dalam memilih asisten praktikum dengan kualitas yang baik.

\section{DASAR TEORI}

\subsection{Big Data}

Konsep Big Data pada dasarnya adalah sebuah "lautan data", dengan banyaknya informasi dan sarana untuk menganalisanya (Trivu dan Ivan, 2014). Big Data merupakan sebuah kombinasi teknologi yang dapat mengelola data yang beragam dalam jumlah besar, dengan kecepatan dan waktu yang tepat dalam keperluan analisis, dan pada saat yang tepat untuk keperluan analisis dan reaksi. Big Data memiliki tiga karakteristik, yaitu volume, velocity, dan variety.

Big Data dideskripsikan sebagai suatu dataset dan teknik analisis di dalam suatu aplikasi yang memiliki jumlah data sangat besar dan juga sangat kompleks. Big Data membutuhkan suatu penyimpanan, manajemen, analisis, dan juga teknologi visualisasi (Chen, Chiang, \& Storey, 2012, p 1161 dalam (Irem, 2016). Menurut McAfee \& Bryjonlfsson, 2012 dalam (Irem, 2016), menerangkan bahwa untuk memanggil data yang begitu besar, dibutuhkan beberapa kategori, terdapat tiga kategori yang memenuhi, diantaranya volume, velocity, dan variety. Dengan masing-masing penjelasan volume merupakan jumlah pada data, velocity menerangkan tentan kecepatan pencarian informasi data, kemudian variety adalah macammacam jenis data misalnya dalam bentuk txt, doc, dan lain sebagainya.

\subsubsection{Mapreduce}

Mapreduce merupakan suatu framework yang digunakan pada aplikasi dan program yang dikenalkan oleh google untuk menjalankan pekerjaan komputasi yang terdistribusi dan dijalankan pada cluster. Konsep yang digunakan dalam Mapreduce adalah fungsi Map dan Reduce untuk functional programming (Industri, 2013).

Hadoop Mapreduce termasuk bagian dari susunan kerja yang dibuat agar lebih mudah dalam melakukan suatu perhitungan. Hadoop Mapreduce ini membuat user untuk bertugas lebih ringan dan berjalan secara sejajar dalam node berbeda, menghemat waktu dalam mengeksekusi keseluruhan.

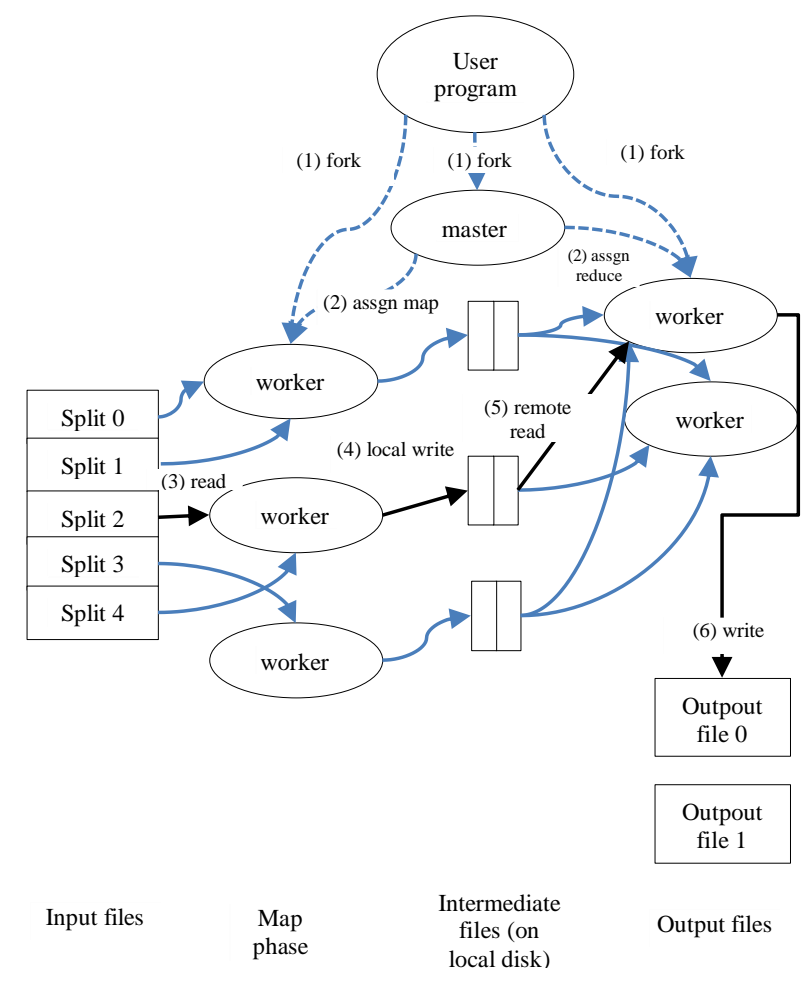

Gambar 1. Mapreduce 


\subsubsection{Multi Node}

Dalam hadoop multi node ini dibutuhkan dua buah komputer, komputer pertama digunakan pada cluster sedangkan komputer kedua digunakan pada slave. Dua komputer ini dikonfigurasi yang merupakan dari mesin dua single node.

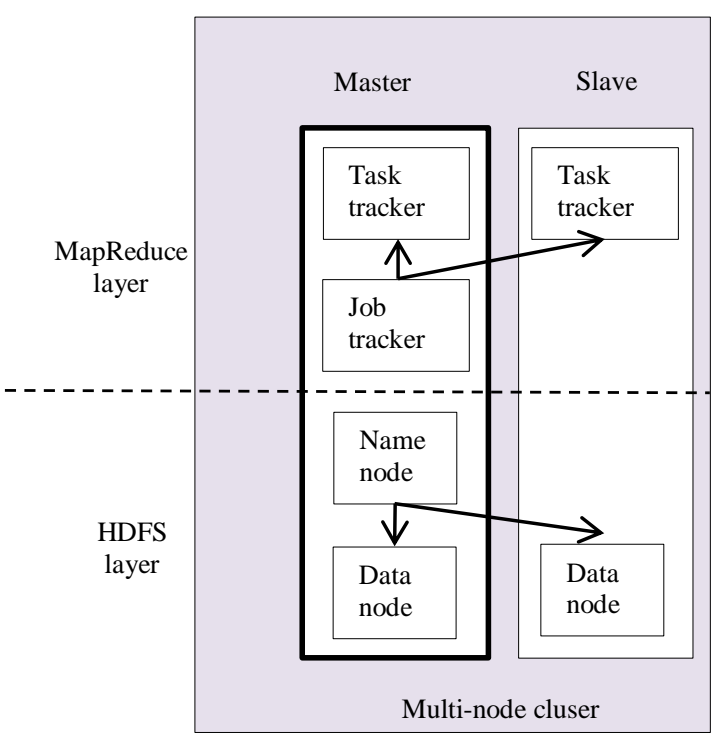

Gambar 2. Hadoop Multi Node

\subsection{Klasifikasi}

Klasifikasi merupakan penentuan objek ke dalam suatu kategori atau kelas. Penentuan objek menggunakan beberapa model (Han, 2006). Dalam memulai suatu klasifikasi data dengan membangun sebuah rule klasifikasi dengan algoritma tertentu yang digunakan pada data training dan data testing.

Pada penelitian ini untuk klasifikasi dalam perhitungannya menggunakan metode Nä̈ve Bayes Classifier.

\subsection{Naive Bayes Classifier}

Naïve Bayes Classifier merupakan penyederhanaan dari teorema Bayes, penemu metode ini adalah seorang ilmuwan Inggris yang bernama Thomas Bayes. Algoritma dalam metode Naïve Bayes didasarkan dengan teknik klasifikasi (Kusumadewi, 2009) dapat dibuktikan bahwa saat kecepatan sangat tinggi dan bersamaan diaplikasikan dalam suatu database dengan jumlah data yang besar, naive bayes mempunyai akurasi dan juga kecepatan yang tinggi (Nugroho, 2009).

Metode Naive Bayesdengan prinsip teorema Bayes mempunyai atribut yang saling berhubungan satu sama lain. Pendekatan yang digunakan teorema bayes yaitu menghitung probabilitas sebuah kejadian pada kondisi tertentu (Lukito \& Chrismanto, 2015). Dasar dari teorema Bayes dinyatakan dalam persamaan (Bustami, 2013).

$$
P(H \mid X)=\frac{P(X \mid H) \cdot P(H)}{P(X)}
$$

Keterangan:

$X \quad$ : Data kelas yang belum diketahui.

$H \quad$ : Hipotesis dari data $X$ yaitu suatu kelas

Spesifik.

$P(H \mid X)$ : Probabilitas Hipotesis $H$ berdasarkan kondisi $X$.

$P(H) \quad$ : Probabilitas Hipotesis $H$

$P(X \mid H)$ : Probabilitas $X$ berdasarkan kondisi $H$

$P(X) \quad$ : Probabilitas $X$

Pada rumus di atas dapat dijelaskan bahwa teorema naive bayes dibutuhkan sebuah petunjuk sebagai proses penentu kelas yang sesuai dengan sampel. Sehingga dibutuhkan kesesuaian terhadap teorema bayes sebagai berikut:

Keterangan:

$$
P(C \mid F 1 \ldots F n)=\frac{P(C) P(F 1 \ldots F n \mid C)}{P(F 1 \ldots F n)}
$$

$C \quad$ : Sebagai kelas

$F 1 \ldots F n$ : Petunjuk atau syarat kondisi

\section{IMPLEMENTASI}

Dalam penyelesaian masalah seleksi pemilihan sistem praktikum di Filkom Universitas Brawijaya, data pada penelitian ini berupa atribut hasil live koding, mata kuliah, hasil mengajar, dan kelas. Kemudian hasil klasifikasi yang didapatkan adalah sangat disarankan, disarankan, dan yang terakhir tidak disarankan.

Implementasi berisi kode program dan tahapantahapan yang dilakukan pada hadoop. Implementasi pada permasalahan seleksi pemelihan asisten praktikum menggunakan bahasa pemrograman java. Dalam pengimplementasian menggunakan tiga class, satu class sebagai map, satu class lain sebagai reduce, dan class lainnya sebagai class main.

\subsection{Kode Program}

Berikut kode program dari kedua class, yaitu class Map.java dan class Reduce.java.

\section{Map.java}

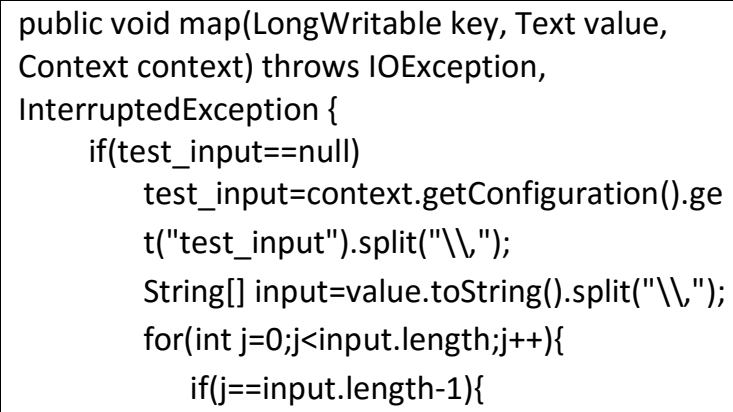




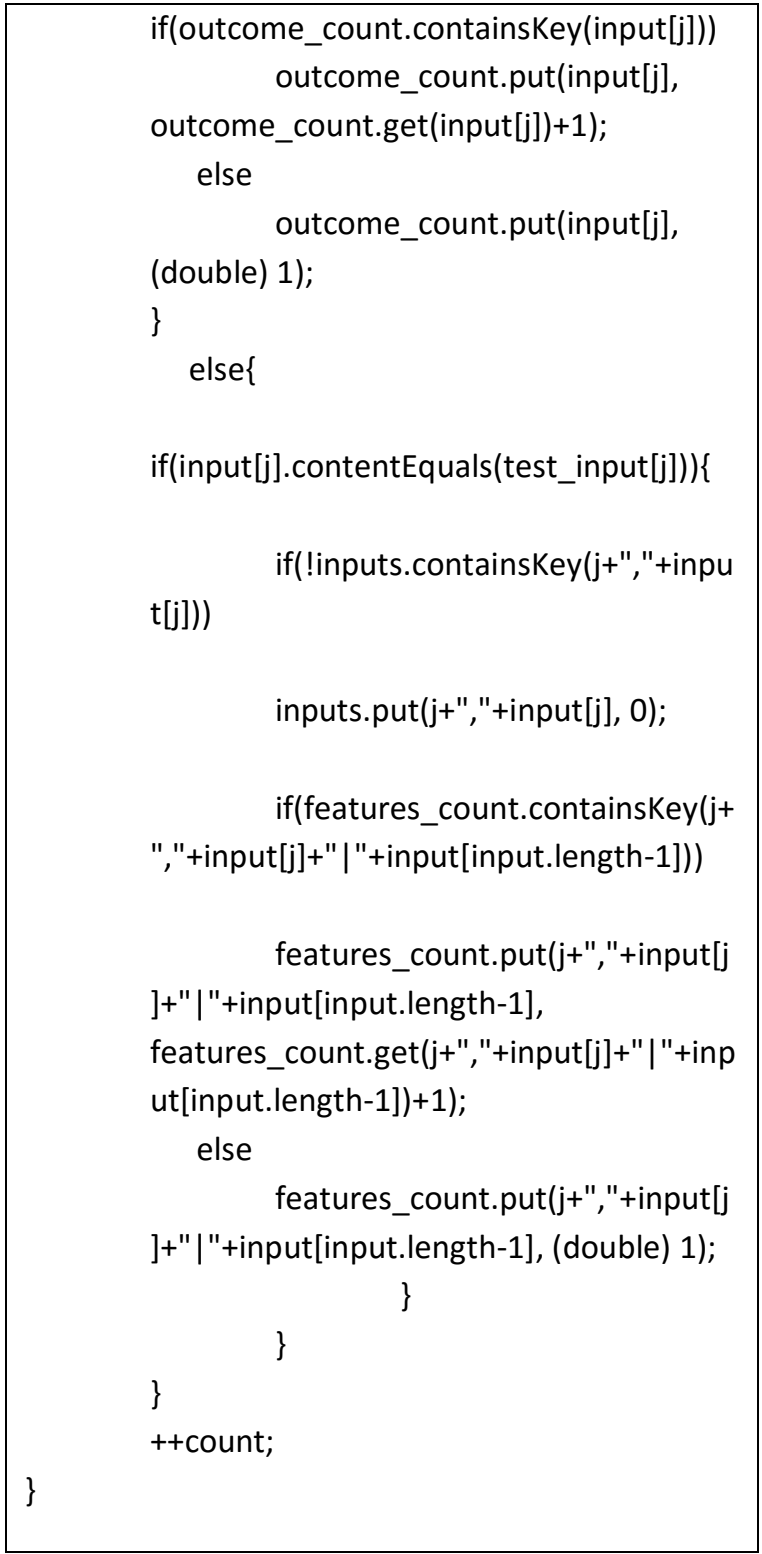

\section{Reduce.java}

public class NBCReduce extends Reducer $<$ IntWritable, Text, IntWritable, Text $>\{$ public void reduce(IntWritable key, Iterable<Text $>$ values, Context context) throws IOException, InterruptedException\{ Double out_value=Double.NEGATIVE_INFINIT Y;

String out_key=null; HashMap<String,Integer> final_output=new HashMap<String,Integer $>()$; for(Text value:values) \{ if(final_output.containsKey(v alue.toString())) final_output.put(value.toStri

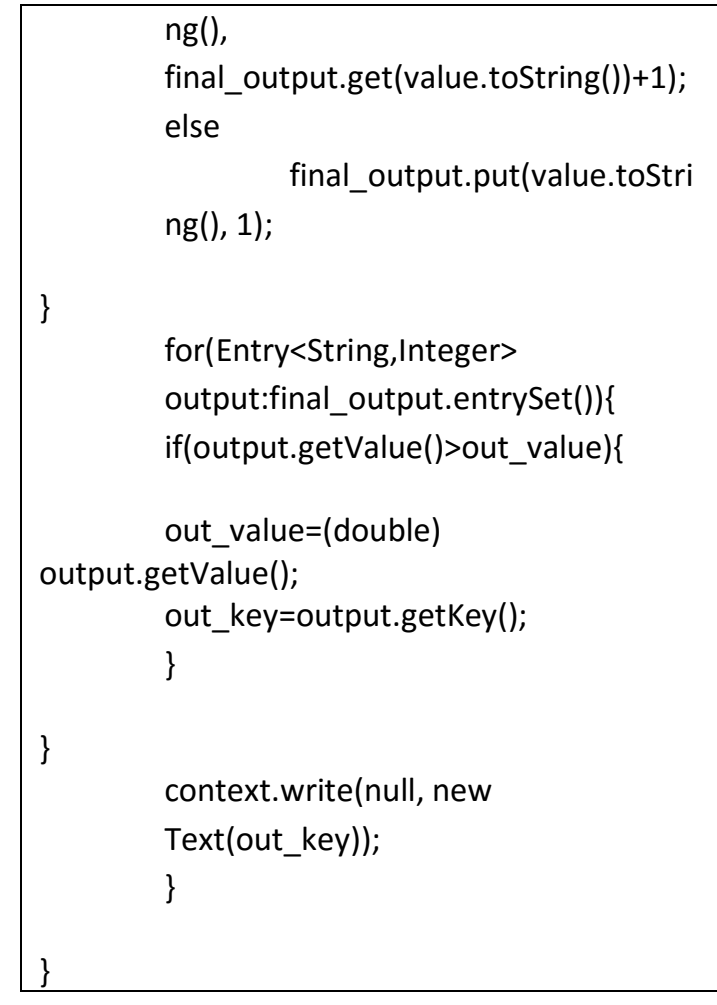

\subsection{Langkah-langkah pada Hadoop}

Langkah-langkah dimulai dari start sampai mengeluakan output dari metode nä̈ve bayes:

1. Ketik start-all.sh

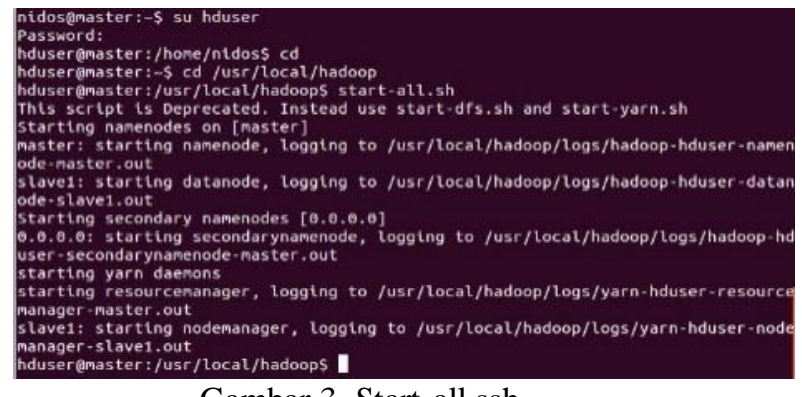

Gambar 3. Start-all.ssh

2. Membuat folder bayes di hduser, kemudian membuat folder input didalam folder bayes houser(Master:/usr/local/hadoops bin/hdfs dfs - -mkdir/user/hduser/bayes hduser(naster:/usr/local/hadoops bin/hdfs dfs - mkdir/user/hduser/bayes/input houser(Mmaster:/usr/local/hadoops I

Gambar 4. Membuat Folder

3. Mengecek folder di localhost:50070

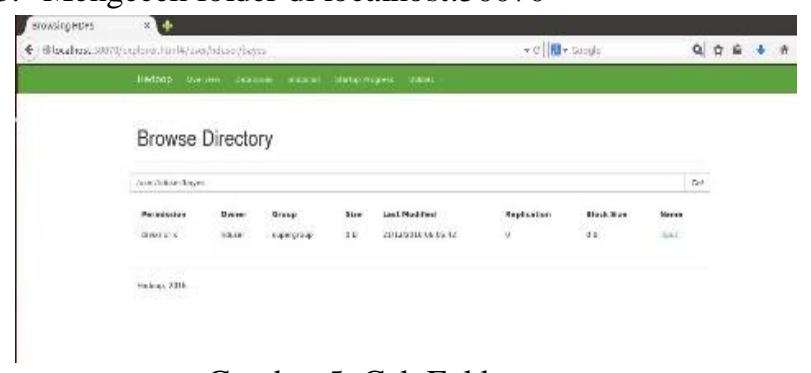

Gambar 5. Cek Folder 
kali ada perekrutan baru pada asisten praktikum sebagai data histori sekaligus data latih, sehingga seiring berjalannya waktu, maka data tersebut akan semakin besar atau masuk pada konteks Big Data. Pada Gambar 17 ditunjukkan bahwa waktu komputasi yang dibutuhkan sangat fluktuatif, karena memang datanya memang masih tergolong masih sedikit dan hanya sebagai simulasi dalam lingkungan hadoop multinode cluster. Selain itu, lama waktu juga tergantung dari aktifitas komputer.

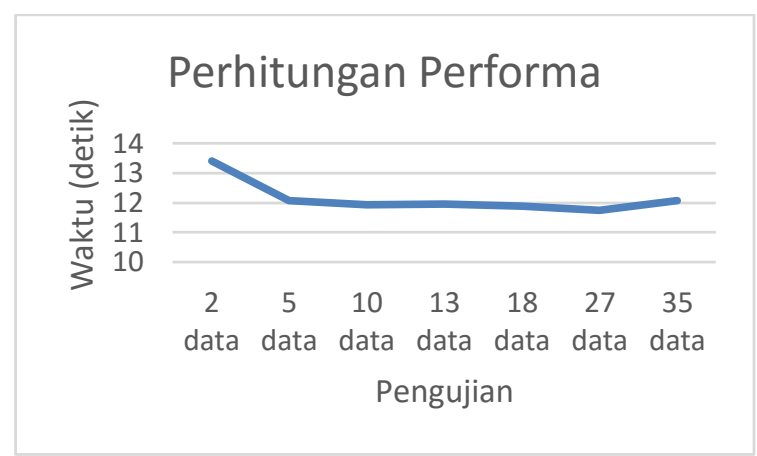

Gambar 17. Grafik Pengujian Performa

Pengujian yang kedua adalah akurasi, hal ini dilakukan untuk melihat kualitas hasil data yang diuji terhadap ukuran seberapa besar kesesuaian dengan data aktual. Akurasi yang dihasilkan yaitu jumlah seluruh nilai yang benar dibagi dengan jumlah data. Hasil yang didapatkan $80 \%$.

\section{KESIMPULAN DAN SARAN}

Kesimpulan yang didapat adalah bahwa dengan menggunakan hadoop multinode dan metode Nä̈ve Bayes yang digunakan untuk klasifikasi pemilihan asisten praktikum dapat diperoleh hasil yang cukup baik yaitu sebesar $80 \%$. Saran yang dapat dilakukan dalam pengembangan selanjutnya yaitu, jumlah data yang digunakan dalam pengujian lebih banyak lagi dan adanya pengujian jumlah node pada PC slaves. Kemudian menerapkan metode lainnya yang ada pada Big Data. Dapat juga dilakukan hybrid atau penggabungan dengan 2 metode atau lebih agar hasil yang didapatkan lebih optimal.

\section{DAFTAR PUSTAKA}

(2013, Oktober). Diambil kembali dari Apache TM Hadoop @ homepage: http://hadoop.apache.org/.

BUSTAMI. 2013. Penerapan Algoritma Naive Bayes untuk Mengklasifikasi Data Nasabah Asuransi.

HAN, J. K. 2006. Concept and Techniques. Morgan Kaufmann.

INDUSTRI, M. 2013. Definisi cloud Computing. Diambil kembali dari Cloud Computing: Meruvian.org
IREM, D. 2016. Classifying Multi-Destination Trips in Austria with Big Data. Elsevier, 22119736.

KALAMSYAH, S. A. 2014. Aplikasi Pendukung Keputusan Seleksi Asisten Praktikum dan Lab Menggunakan Metode Analytical Hierarchi Process (Studi Kasus: Lab Informatika Universitas Telkom).

KUSUMADEWI, S. 2009. Klasifikasi Status Gizi Menggunakan Naive Bayesian Classification.

LUKITO, Y., \& CHRISMANTO, A. R. 2015. Perbandingan Metode-Metode Klasifikasi Untuk Indoor Positioning System. Jurnal Teknik Informatika dan Sistem Informasi, 2.

SHOLIHAH, A. 2013. Sistem Penentuan Uang Kuliah Tunggal (UKT) Menggunakan Metode Naive Bayes Classifier.

SOEMARSO. 2003. Akuntansi Suatu Pengantar. Jakarta: Salemba Empat. 